\title{
Public Intellectuals in Digital and Global Times: the Case of Project Syndicate
}

\author{
Mauro Basaure $^{1} \cdot$ Alfredo Joignant $^{2} \cdot$ Rachel Théodore $^{3}$ D
}

Accepted: 28 January 2022

(c) The Author(s), under exclusive licence to Springer Science+Business Media, LLC, part of Springer Nature 2022

\begin{abstract}
In this article, we present a conceptual model for the study of intellectual trajectories. The notion of trajectory combines the figure of the intellectuals, as actors, and the stages on which they act. With the help of this model, we seek particularly to study the figure of the global digital public intellectual and the global digital stage on which this figure operates. By studying the case of Project Syndicate (the most important global platform or stage for the circulation of ideas through opinion columns), we show empirically that this stage has particularities that make it a circuit for such circulation. The notion of circuit seems to us more appropriate than field to describe this type of global stage at a transnational scale, still characterized by a lower level of institutionalization.
\end{abstract}

Keywords Public intellectuals · Trajectories · Circuits · Field · Project syndicate

Every intellectual operates on a materiality. This takes the form not only of institutions but also technologies that make it possible to transmit ideas and generate audiences. In classical times, this materiality involved the printing press and books but, today, also includes a series of digital tools through which linguistic and geographic barriers can be surmounted at a speed that was unthinkable only a few decades ago. This change can be underscored by differentiating between a codex or typewriter era and a post-codex or internet era (Burnham, 2014, 2018). This raises the question of how the figure of the public intellectual has changed between these two eras, a

Rachel Théodore

rachel.theodore@umayor.cl

1 School of Social Sciences, Associate Researcher at the Center for Social Conflict and Cohesion Studies (COES), Universidad Andrés Bello, Santiago, Chile

2 School of Political Science, Principal Investigator at the Center for Social Conflict and Cohesion Studies (COES), Universidad Diego Portales, Santiago, Chile

3 Centre for Economics and Social Policy, Universidad Mayor, Providencia, Santiago de Chile, Chile 
subject that is nowadays almost a field of research in its own right (Baert \& Booth, 2012; Burnham, 2018; Townsley, 2015).

This article examines conceptually and through a case study the figure of the global digital public intellectual, precisely in terms of the institutional and technological stage on which this figure operates. The intellectual and the stage are inseparable so that, without falling prey to technological determinisms, we assume that, when we talk about global digital public intellectuals, we are also talking about a global digital platform of which we analyze a concrete example: the Project Syndicate platform (hereinafter $P S$ ). This platform is global and, at the same time, constitutes a specific form of circulation with thematic and geographic particularities (among others): global digital circuits.

We take $P S$ as an empirical case based on our research into this platform. It is only one example of the vast sphere of opinion and different stages, but is particularly fitting as a case study. What makes it original and groundbreaking is that it brings together dozens of public intellectuals who share their opinions and columns through it. It describes itself as "The World's Opinion Page" and it is, indeed, the world's largest op-ed website (see The Year Ahead 2019 on Project Syndicate's website). $P S$ refers to its articles as “commentaries" because they express the author's views on a specific topic. It publishes original commentaries by prominent economists, political leaders, scholars, business leaders, writers, and civic activists, reaching a global audience through over 500 media outlets in over 150 countries. This makes it the most interesting and relevant platform for studying this public intellectual figure and the new way in which ideas are generated and exchanged.

We begin this article with a characterization of the figure of the global digital public intellectual and the stage on which this figure operates (Stages and Digital Global Public Intellectuals). In the second part, we present a theoretical model for analysis of the figure of the intellectual and its transformation over the years (A Theoretical Model for Studying the Figure of the Public Intellectual). In the third section, we seek to better understand a relatively new, but important figure that has emerged with force since the appearance of the internet: the "global and digital public intellectual" (The Public Global Digital Circuit). In the last section, we propose a case study of this new emerging figure by analyzing the PS platform (Project Syndicate as a Digital Global Public Circuit).

\section{Stages and Digital Global Public Intellectuals}

Russell Jacoby apparently coined the notion of "public intellectual" in 1987 in The Last Intellectuals. However, public intellectuals existed prior to this. To better grasp this ever-changing figure, we need to go back to the dark nineteenth century in France when Émile Zola published his famous J'accuse amid the anti-Semitic Dreyfus affair, in which he took a strong anti-government position. This marks the beginning of an intellectual taking a public stance and, since then, the notion has greatly evolved.

Indeed, what does Zola's open letter in L'Aurore, written and published in ink and paper in 1898, have in common with a 2008 opinion column by Nobel laureate 
in economics, Joseph Stiglitz, published digitally on the internet by PS? What these two intellectuals share, over a century apart, is that they took a political position and defended their ideas publicly. Or, as Jacoby put it, public intellectuals are "writers and thinkers who address a general and educated audience" (Jacoby, 1987, p.5). A crucial difference is that Zola was what we will call an "analog" intellectual, using old-fashioned methods such as paper, books, and libraries, whereas Stiglitz is not only an analog intellectual but also a "digital" one in that he uses tools such as the internet and computers. Burnham (2018) refers to the change from the typewriting era to the internet era, not as a purely technological change, but as one that generates transformations in the intellectuals themselves as well as their practices. Therefore, there are intellectuals, like Zizek, that we can only understand in the internet or postcodex era, in which audiovisual material has a greater impact than text material.

This is the great novelty of the late twentieth century and the beginning of this century; thanks to technological progress, intellectuals now have the possibility of being read in a matter of days by millions of individuals around the world. During "analog" times, there was already a foreshadowing of the quick and global spread of ideas through digital media; however, this depended on the "famousness" not only of who wrote but also of where they were published. Said (2005, p.21) noted that "an article I might write in New York for a British newspaper has a good chance of reappearing on individual websites or via email on screens in the United States, Japan, Pakistan, Middle East, South Africa, as well as Australia. Authors and publishers have very little control over what is reprinted and recirculated." Moreover, with the COVID-19 pandemic, humanity has entered a new period of digitalization and interdependency, whose implications are only just beginning to grasp (Basaure et al., 2021). Intellectual work is part of this new digital era, and it is essential to analyze the new emerging figure of the global public intellectual and how ideas circulate.

The notion of public intellectual also refers to a type of agent who seeks to influence the course of events that affect society. Various definitions and classifications of intellectuals are emerging in public spheres (Fleck \& Hess, 2014). Indeed, distinct concepts are concealed within different classifications. Gans (2001) distinguishes between "the generalists, the pundits" and "the disciplinary public intellectuals" while Oosthuizen (2021) distinguishes between "political public intellectuals," "cultural intellectuals," "academic intellectuals" and "organic public intellectuals". Here, we will not enter into an epistemology of the notion but rather characterize our understanding of it. In this article, we define public intellectuals as having at least four essential features: first, the personal resources which result from their national and/or regional intellectual trajectory; second, a performative intervention that reflects different regional or global contexts (Baert, 2012; Baert \& Booth, 2012); third, the scale of their readership, ranging from domestic to worldwide; and fourth, the matter of what is "public" and their public (Warner, 2002).

We do not define "public" as opposed to "private" or "common," but as what is or becomes important for the public in different contexts, which is then configured as an "audience". This public is neither static nor permanent, and certain situations can produce its concentration, as in "captivating the public's attention" around issues that become relevant, which is also partly explained by the performative logics of 
intellectual intervention (Bar-El \& Baert, 2021). Thus, when a crisis arises, whether political, social, or economic, this historical event gathers a public around a specific topic, and the public intellectual intervenes, either to subvert the order or - a matter that is sometimes forgotten - to reproduce or preserve it (as, for example, in the case of "public intellectuals at the service of Trump": Swartz, 2021). These crises can thus generate the appearance of new public intellectual figures or contribute to re-validate others who already dominated the academic or media field, or both. For instance, it was during the 2008-2009 crisis and the growing concentration of wealth and income that an economist like Piketty (2013) could become a global public intellectual by publishing his book Le capital au XXIème siècle, whose arguments made sense beyond the community of economists (Brissaud \& Chahsishe, 2017). It was also during a crisis (of Keynesianism) that the figures of Hayek and Friedman could emerge. Once the monetarist revolution and its political expression in the governments of Pinochet, Thatcher and Reagan were consolidated, they became intellectuals of order and the new economic orthodoxy (Mirowski \& Plewe, 2009; Stedman Jones, 2012).

From another standpoint, the public intellectual is someone who intervenes politically by taking positions, both on the national stage and, for those who are successful, a transnational (some say "supranational," see Korom, 2014) intellectual stage. (In this regard, Zelinsky is right when he says that the literature on public intellectuals is beguiled by the charisma of those who have been successful, overlooking the existence of trajectories in which nothing guaranteed success: Zelinsky, 2020, p.2). At the transnational level, we use the term "stage" and not "field" since the latter has a much weaker connotation outside national borders in terms of institutionalization (Buchholz, 2016; Krause, 2018; Sapiro, 2013; Sapiro et al., 2018). This was an important conceptual decision. We opted to abandon the notion of "intellectual field" on a transnational scale in favor of the category of "stage" (transnational intellectual) derived from Goffman's sociology. We do not rule out the usefulness of the notion of "field," but understand its limits and when it ceases to be relevant. We note that authors in this field frequently use the notion of "capital," extending its meaning to give it a global or transnational dimension in a digital age but, symptomatically, do not do the same with the notion of "field". Examples of the former include the concepts of "generalized social capital" (Schwarz, 2021) and "celebrity capital" (Driessens, 2013).

The "stage" category underscores both the prominence of certain global public intellectuals and the shaping and presentation of the ideas and positions that are propagated through specific circuits (which we refer to here as "digital global public circuits"). The concept of stage has the added advantage of emphasizing the emergence of transnational platforms. Indeed, these new types of twenty-first-century

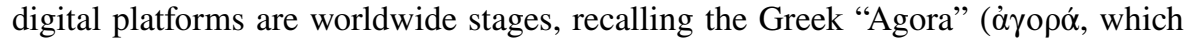
means "reunite"), a social and political forum where citizens discussed ideas of all types (Finley, 1983; Manin, 1995; Ober, 2007). It is important to note that our focus is not on the public, in the sense of audience, but on the intellectuals and the transnational stages on which they act.

What we understand by "transnational intellectual stage" is, therefore, characterized by the following features: 
1. It is formed by public intellectuals and its vocation is to transcend the national borders within which the intellectuals originally emerged.

2. Public intellectuals tend to intervene on this stage through the exploitation of social networks and digital devices, adapting not only their performances but also the format of their interventions.

3. Public intellectuals operate through these media and platforms, which are ever more institutionalized (that is, increasingly consecrated as reflected in the growing number of quotes from intellectuals who publish on digital platforms).

4. Global digital public intellectuals publish their work through circuits that produce and disseminate ideas ("digital global public circuits") in which translators, commentators, popularizers, and platform audiences participate.

5. These circuits have three crucial characteristics: they constitute particular circulation trajectories in a thematic and geographic sense, the subjects they cover are of international relevance, and they involve translation into several languages.

6. Local intellectuals often discuss the work published by these global public intellectuals and it, therefore, has repercussions at the domestic level.

A study of transnational audiences is far beyond the scope and objectives of this paper. It is, however, important to note that, although the digital age assumes the global expansion of connections and, therefore, of audiences, this globality is far from reaching the vastness of the real world. Important parts of the world, especially the so-called third world, are very much disconnected. The sole idea of "globality" conceals this worldwide digital gap. By using the term "circuit," we underline the existing biases in the global media space of opinion, but must also stress that a large part of the world population does not participate in it. This is a problem that cannot be solved by the translations such as those used by $P S$.

\section{A Theoretical Model for Studying the Figure of the Public Intellectual}

We base our theoretical model on two conceptual figures that, in principle, could be studied separately but which we relate because "actors" always operate on a given "stage". As an example, we have, on the one hand, the "intellectual" as a specific actor in the national field - for instance, we could think of the local analog intellectual as opposed to the global digital public intellectual - and, on the other, the "stage" where this actor operates - here, the global and digital public circuit. This logic of intellectual/stage, which articulates our conceptual framework, coincides in a structural sense with that of those who - following Bourdieu's perspective investigate how public intellectuals act by mobilizing capital. This can be done in the media space of opinion (Townsley, 2015) and in the digital space (Schwarz, 2021). We also agree, in this structural sense, with the pragmatist perspective, according to which intellectuals position themselves through performative interventions in specific contexts, which today are characterized by the digital age, the culture of celebrity, and the decline of the classic intellectual figure (Baert, 2012; Baert \& Booth, 2012; Bar-El \& Baert, 2021). 
We, therefore, conceptualize a theoretical model to analyze how we can classify today's intellectuals and how they relate to different types of stages. We articulate our theoretical model based on three different logics: field, geographic level, and transmission.

\begin{tabular}{|c|c|c|c|c|c|c|}
\hline \multicolumn{2}{|l|}{ Field logic } & \multicolumn{3}{|c|}{ Geographic level } & \multicolumn{2}{|c|}{ Transmission logic } \\
\hline $\begin{array}{l}\text { Academic } \\
\text { intellectual }\end{array}$ & $\begin{array}{l}\text { Public } \\
\quad \text { intellectual }\end{array}$ & $\begin{array}{l}\text { National } \\
\text { intellectual }\end{array}$ & $\begin{array}{l}\text { Regional } \\
\text { intellectual }\end{array}$ & $\begin{array}{l}\text { Global } \\
\text { intellectual }\end{array}$ & $\begin{array}{l}\text { Analog } \\
\quad \text { intellectual }\end{array}$ & $\begin{array}{l}\text { Digital } \\
\quad \text { intellectual }\end{array}$ \\
\hline
\end{tabular}

Under the first logic, the field, we seek to distinguish between an "academic intellectual" and a "public intellectual". The notion of "public intellectual" stresses the "public" relevance of the figure and we use it in contrast not to "private" but to "academic," although a public intellectual may, of course, be an academic. Intellectuals can also operate in other fields, such as the political and journalistic fields, both of which place them within the media space of opinion (Townsley, 2015). In our research, we focus on the distinction between public and academic intellectuals since, as we will see, our case study refers particularly to these figures. It is important to note that academics do not necessarily have to stand out for their convictions; they do not have to address important public matters, nor do they have to reach out to a more or less broad audience in order to exist. Nonetheless, an academic who is not (yet) a public intellectual may become one. In other words, it is not essences that are involved, but a concept that refers to the agents' trajectories.

Following the logic of geographic level, we differentiate between "national," "regional," and "global" intellectuals. We frame the national intellectual within the limits of a country or nation while the regional intellectual operates at a transnational level, whether in terms of language (Latin America, English-speaking world, etc.) or tradition (European, Arab, etc.). It is the global intellectual who transcends language and regional barriers and for whom the question of translation is, therefore, key (Casanova, 2002, 2008).

Finally, the last logic, transmission, refers to how the intellectual's work is produced and disseminated. Using a metaphor from photography, we distinguish between an "analog" and a "digital" intellectual. By analog, we mean that the intellectual uses traditional methods of dissemination, based on written text on paper ("old-fashioned"), such as books, libraries, pens, and papers and publishes in paperback books or articles whereas the digital intellectual mainly publishes using computers and the internet. Of course, some multi-range intellectuals operate in both ways, publishing paperback versions of their work while also being active online.

This model allows us to be sensitive to changes in intellectuals' status and reputation, which can be explained by trajectory effects within a field, the geographic and (multi) linguistic scope of the agent's production and, eventually, the use of digital technologies to propagate ideas, problems, and concepts. This analysis model is complex in that it permits multiple combinations and dynamics, implying that the combinations are not static. The differences are not exclusive so the combinations can consider elements not only from different logics but also within the same logic. What this model describes is a multi-scale continuum along which intellectuals can 
be located, without this implying that they are destined to remain in one zone of the continuum. Therefore, we can find intellectuals who are "only" academics because they have no other defining characteristics while, at the other more complex end of the continuum, we find digital intellectuals, who also operate in an analog manner (transmission logic), nationally, regionally, and/or globally (geographic level) and do so as public intellectuals but are also active in the academic field (field logic).

Using this model, we can list intellectuals within this gradient of complexity, from the simplest to the most complex space of the continuum. Between these two extremes, we find many positions and combinations. Michael Sandel, for example, has a trajectory that covers the entire continuum, from analog academic national to operating on a digital global public stage, with this latter phase built on several previous phases. "Sandel has become one of the most famous public intellectuals and debaters in the English-speaking world, taking a berth at Harvard after receiving a doctorate as a Rhodes scholar in Oxford. He has been described as 'a philosopher with the global profile of a rock star', reaching audiences of millions online from his Harvard base. Listeners to his BBC Radio 4 series, The Public Philosopher, will have become familiar with the Socratic style of questioning, as Sandel artfully tests the assumptions in the arguments of his audience. Millions of YouTube viewers, where his lectures on justice can be freely accessed, will be familiar with the high, serious forehead and gentle, softly spoken delivery" (The Guardian, 6 September 2020). Sandel is an excellent example of how an intellectual can simultaneously inhabit the codex and post-codex eras, to use the concepts of Burnham (2018).

Certainly, there are also trajectories of other types that are marked by the historical moment in which the intellectual lived. Given the time in which he lived, when internet was not as developed as it is today, Pierre Bourdieu could operate as an analog, but not digital, global public intellectual. We could describe his trajectory in the dynamic terms of a progression from an analog national academic intellectual to an analog national public intellectual, followed by a transition to analog global academic intellectual and analog global public intellectual.

Most of the great intellectuals of the twentieth century were global analog public intellectuals. However, there were also public intellectuals whose transmission logic was both analog and digital, but who operated at the regional level - for example, the Spanish- or French-speaking world - beyond which they were relatively unknown. This continues to be a trait of certain public intellectuals, unknown outside their national or regional areas or their tradition. In this sense, language barriers are crucial in explaining why certain public intellectuals are relatively unknown outside their linguistic area. This does not mean, however, that everything is reduced to a translation problem. For example, Moisés Naím, a renowned Venezuelan writer and columnist with a long international journalistic career, is published by media that have a broad distribution and are, therefore, more global - such as The New York Times, Newsweek and Time — but his ideas circulate fundamentally in the Ibero-American world and he is, therefore, more a regional public intellectual than a global one.

Until well into the twentieth century, the highest complexity that could be achieved within the scheme presented here was the analog global intellectual. Today, thanks to the technological development of the internet (blogs, YouTube channels, 
and podcasts), the possibility of a new extreme is opening up, adding (to the analog global characteristic) the digital one. Certainly, there are combinations that, as Max Weber would say, are "elective affinities" and are possible only in certain historical contexts. Typically, the more complex categories of this continuum are built on having already reached less complex positions; they do not emerge out of nowhere or thanks to technological determinism.

Today, the digital world, together with faster global accessibility thanks to machine translation, has reduced language barriers. Outside the digital realm, the barriers are overcome by translating into English or several languages, an issue in which the publishing market is central. Translation in times of the internet and the digital society is a field of research in itself, which we cannot address here. In this study, we presuppose that there was a shift from the individual model of translation (a modern model which arose in the fifteenth century) to a collective model, which corresponds to the classical model or the way to translate prior to the individualization of translation (Shenhav-Shahrabani, 2019).

However, the opportunity to reach new geographic levels is determined not only by linguistic or technological factors: issues such as the provincialism of the topics of reflection, the idiosyncrasy of intellectuals' motivations, the connections that keep the intellectual enjeux with what is at stake in the political field and the status of "celebrity intellectual" also play an important role. In this sense, the technological dimension is necessary but not sufficient for the emergence of the figure of the global digital public intellectual. These intellectuals must also address issues of global relevance: this is the case of Pierre Bourdieu, who achieved the category of "global thinker" when, in the last 10 years of his life, he addressed the subject of neoliberalism. This does not seem to be a coincidence. We believe that the figure of the public intellectual typically emerges in crisis situations (Joignant \& Basaure, 2021), which does not imply that public intellectuals of order cannot emerge on the perimeter of these same crises. Thus, a national crisis sees the emergence of national public intellectuals and a global crisis sets the stage for the emergence of global public intellectuals.

In this study, we focus on a particular figure that is constructed from the combination of, at least, the following elements: Public-Global-Digital. We assume that this combination also contains other elements. Empirically, intellectuals who coincide with this complex figure are also analog, recognized regionally and nationally, and many of them also have recognized academic work.

\section{The Public Global Digital Circuit}

To complement the model presented above, we need to examine the different "stages" on which the actor-intellectuals operate. With digital global public intellectuals, the stages are many and diverse, each of them representing a different level of institutionalization. This reflects several elements, analyzed here according to the same logic described above. 
The stages on which academic intellectuals operate are more institutionalized than the fields in which public intellectuals act; the national space (field logic) is more institutionalized than the regional space and certainly than the global space (logic of geographic level); the analog stage is more institutionalized than the digital stage (transmission logic). For example, analog academic intellectuals work within a vast network of structures that interconnect in the actual world as opposed to the digital one.

To analyze the levels of institutionalization of the various stages and fields, we propose the following scoring system: following the logics described above, we give a higher score to stages that typically show a higher degree of institutionalization. For example, the space in which the academic intellectual operates (university and research system) is more institutionalized than that in which the public intellectual operates (typically the media). Hence, the former receives a score of 2 points and the latter a score of 1 . We perform the same operation for the geographic and transmission logics. The global space is less institutionalized than the regional one, and the latter less than the national one so they receive 1,2 , and 3 points, respectively. In the case of the transmission logic, analog has a higher level of institutionalization than digital, so it receives 2 points while the latter receives only 1 . The following table shows this scoring system.

\begin{tabular}{lllllll}
\hline Field logic & \multicolumn{3}{c}{ Geographic level } & \multicolumn{2}{c}{ Transmission logic } \\
\hline Academic & Public & National & Regional & Global & Analog & Digital \\
intellectual & intellectual & intellectual & intellectual & intellectual & intellectual & intellectual \\
2 & 1 & 3 & 2 & 1 & 2 & 1 \\
\hline
\end{tabular}

Based on this, we establish a series of complex interactions. Theoretically, there are 12 possible combinations, each with a certain score. For example, the academic ( 2 points)/national (3 points)/analog ( 2 points) intellectual has an institutionalization score of 7 points. In this way, we obtain a continuum with two extremes: the highest level of institutionalization is the "academic-national-analog" combination (7 points) and the lowest level is the "public-global-digital" combination (3 points). Between these two poles, it is possible to describe several relatively institutionalized and objectified stages.

It is important to remember that the emphasis here is on the institutionalization of the stage or field where the different intellectuals typically operate, not on the figure of the intellectuals themselves. Within the framework of this analytical proposal, we affirm that the traditional concept of intellectual field, in the Bourdieusian sense, is better adapted to higher levels of institutionalization (i.e., on a national scale) and loses its analytical potential as their institutionalization diminishes. Where this occurs, we consider the concept of "circuit" to be more appropriate. The following table illustrates and summarizes the above. 


\begin{tabular}{|c|c|c|c|c|c|}
\hline \multirow{3}{*}{$\begin{array}{l}\text { Degree of } \\
\text { institutionalization } \\
\text { Field or circuit } \\
\text { continuum } \\
\text { Score-combination }\end{array}$} & \multicolumn{5}{|c|}{ 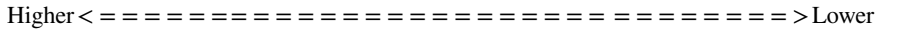 } \\
\hline & \multicolumn{5}{|c|}{ Field $<======================+$ Circuit } \\
\hline & 7 & 6 & 5 & 4 & 3 \\
\hline Different stages & $\begin{array}{l}\text { Academic/national/ } \\
\text { analog } \\
\text { Public/national/ } \\
\text { analog }\end{array}$ & $\begin{array}{l}\text { Academic/ } \\
\text { regional/ } \\
\text { analog } \\
\text { Academic/ } \\
\text { national/digital }\end{array}$ & $\begin{array}{l}\text { Academic/ } \\
\text { global/analog } \\
\text { Academic/ } \\
\text { regional/ } \\
\text { digital } \\
\text { Public/regional/ } \\
\text { analog } \\
\text { Public/national/ } \\
\text { digital } \\
\text { Public/regional/ } \\
\text { digital }\end{array}$ & $\begin{array}{l}\text { Academic/ } \\
\text { global/digital } \\
\text { Public/global/ } \\
\text { analog }\end{array}$ & $\begin{array}{l}\text { Public/global/ } \\
\text { digital }\end{array}$ \\
\hline
\end{tabular}

This model of analysis is purely theoretical and serves as a heuristic function to compare dissimilar intellectual trajectories from the perspective of our model. Compare, for example, the trajectories of Pierre Bourdieu and Thomas Piketty at different historical moments in which this continuum can be applied. Bourdieu was an analog national academic, then an analog national public intellectual, before becoming an analog global academic and, finally, an analog global public intellectual. He did not reach the status of global digital public intellectual because, at the time of his death (in 2002), mass use of the internet and social networks was only incipient (a time we place on the perimeter of the dot.com bubble between 1997 and 2001). Thomas Piketty, the French economist, moved through similar phases. He was first and foremost an analog national academic and, in 2013, achieved the status of analog and digital global public intellectual with his best-seller Capital in the Twenty-First Century, since he publishes both paperback books and runs a blog with digital columns in French and English. In both these trajectories, translation was essential in bridging language barriers and reaching a global audience. In the analog dimension, translation times have certainly shortened (compare those for Bourdieu's work and that of Piketty) but are incomparably faster in the digital world. The notion of trajectory is very relevant for understanding our model, since we not only consider the variety of intellectual biographies and conceive a dynamic model but also connect to those who study these trajectories, accentuating the pragmatic moment when intellectual actors use a performance in order, for example, to boost their trajectory to a more general or global level or expand their radius of action (Baert, 2012; Baert \& Booth, 2012; Bar-El \& Baert, 2021).

In most cases, intellectuals operate simultaneously on several of these stages and fields. Indeed, this is often why their work is recognized as having a certain "greatness". The most institutionalized stages (particularly, national intellectual fields) often serve as a springboard from which to reach other less institutionalized stages. In a typical trajectory, an intellectual is a prominent national scholar before becoming a national public intellectual, or a prominent global scholar before becoming a global public intellectual. 
This descriptive and analytical exercise could be repeated for different trajectories. This hierarchy of institutionalization is theoretical and referential. However, in both extreme cases, it is difficult to be mistaken. There is little doubt that the analog national academic field is highly institutionalized and reflects a long tradition anchored in universities, research centers, think tanks, etc. At the same time, it seems undeniable that the stage for digital global public intellectuals is an emerging stage that has empirical reality in online platforms with at least two characteristics: they seek to overcome the language barrier through translation, and they respond to the urgent need for explanation and understanding of global crises, without surrendering to the mere analysis of contingency.

Take the concept of the "field" and its greater suitability for more institutionalized stages. It has also been used to describe certain "transnational fields," many of them corresponding to linguistic areas (Hispanic, Anglo-American) or territorial limits (Europe, Latin America) or, sometimes, "transnational fields" on a world scale, such as international law (Dézalay \& Garth, 1996, 2002). Although Bourdieu himself did not use this concept to address the transnational phenomenon, there are several studies where it is used in this sense (Bourdieu, 1989, 2002). These studies defined the basic elements of a "field": it supposes a relatively autonomous space (not necessarily a physical place) in which relatively regulated competitive relations between actors are displayed and that is dynamically structured in terms of domination based on the accumulation of different sorts of capital.

These elements are not clear in the case of the public-global-digital stage, so it would be wrong to speak of a "global field". Indeed, the increasingly digital stages on which global public intellectuals intervene lack several of the properties and situational logics that characterize a field. We argue that global public intellectuals operate on a "global" intellectual stage that is undergoing an emerging process of institutionalization, of a digital order, for which the notion of "circuit" is far more appropriate. This does not mean that the intellectual actors who operate on it do not also operate in certain national fields, whether academic, journalistic, or political. It merely shows that this stage is not configured as a field according to the above definition. The notion of field does not describe the emerging phenomenon of intervention by public intellectuals of a new type, particularly when this occurs on a global scale and through new media. In any case, it is striking to observe that, when referring to the global circulation of ideas in the digital age, authors do not use the concept of "field" (we believe because it is not suited to the global level) but, instead, use the notion derived from the concept of "capital" (Driessens, 2013; Schwarz, 2021).

There is a correlation between the appearance of a new global public intellectual and the new means of communication. We take the view that the appearance of digital media (websites, podcasts, online versions of newspapers and magazines, video platforms, etc.) has permitted the appearance of global public intellectuals whose symbolic production can have political and intellectual influence. This is particularly the case in situations of crisis that permit the diversification of public intellectuals' "modes of public engagements" in a "space of opinion" (Eyal \& Buchholz, 2010, p.124) that is nothing other than a circuit for the propagation of ideas and conceptions of reality. In other words, the supports for their production and dissemination 
have undergone a profound transformation (mass use of online communications devices such as smartphones, tablets, Kindle). There has been a veritable explosion of the modes of intervention: (a) interviews in the written press and magazines for enlightened audiences; (b) television interviews and documentaries; (c) interviews and interventions at protest events broadcast on YouTube channels (Nancy Fraser and Judith Butler on the Occupy movement); (d) columns in the written press; (e) radio (the role played by the Fox network in the USA); (f) blogs, podcasts, and all kinds of electronic communication; and (g) webinars and live conversations. All these forms of intervention are not mere means; in addition to opening up new possibilities, they limit and, therefore, transform what is communicated, as well as the figure of the person who communicates, i.e., the public intellectual. For instance, Townsley (2015) highlights the figure of the columnist and the column as a format that determines the form of intervention, referring to the intellectual who writes columns in the media opinion space as "media-intellectual".

There is, therefore, a correlation between the appearance of global public intellectuals and the "digital global public circuit"; however, this does not mean that technology determines the emergence of digital public intellectuals. For this type of intellectual to emerge, individual and pragmatic positioning strategies are required (Bar-El \& Baert, 2021), as well as openings and what Joas called the "creativity of action" (Joas, 1996). To further develop this idea, we will characterize an empirical example, the PS platform, and how it enables the emerging figure of the digital global public intellectual.

\section{Project Syndicate as a Digital Global Public Circuit}

$P S$ was founded in 1994 in Prague. At first, it was called "Privatization Project" and was run by researchers from Columbia University. It originated as an exchange platform, and the founders began creating links between newspapers from their headquarters in Prague. Certain newspapers were then under Communist control and of poor quality so the project asked local authors for their opinions and then approached people from outside the region to write about certain topics. Soon enough, it caught the attention of a newspaper in Vienna, which asked to buy its columns. Thus, "Project Syndicate" was born.

There are few studies on $P S$, making this contribution to the sociology of the intellectual field and the public arena even more relevant (a content analysis of the metaphors of popular economic discourse in English and Arabic on some websites includes $P S$, see Shehab \& Nazzal, 2020) The most prominent existing study is the analysis of Korom (Korom, 2014), who describes the composition, origin, and affiliation of PS contributors (universities, think tanks, etc.) and looks in depth at the columns' contents and their relation to the contributor's function. As our research also shows, Korom concluded that "ProSyn can be regarded as one of the most influential newly emerging spaces of public intellectual activity" (p. 242).

We present this platform by analyzing it first as a global stage (1) and then the intellectuals operating on it (2). An example is used to illustrate the combination 
of these two elements involved in the notion of a global digital public intellectual and stage (3). The notion of circuit here means precisely that this globality is not "universal" or "total". Rather, because of certain factors, the specific paths through which ideas circulate mean that circulation is at the same time global and particular (4).

1. A feature that makes this platform unique is the particular combination it achieves between distribution and translation: its translation system and the global "circuit" that derives from it. The platform is a print syndication system under which newspapers are syndicated to it. There are individual and newspaper subscriptions. Newspapers can subscribe to a "pack" of some 70 columns per year. The novelty is that, for each newspaper with a paid subscription, $P S$ offers a free subscription to another newspaper that cannot afford it. Its policy is not to leave anyone out, even if they are unable to pay for the columns. In total, there are 508 syndicated newspapers of which 265 do not pay. The newspapers have exclusive rights to columns and can access the platform's files and also receive other special benefits.

All columns are written directly in English or, when in another language, such as German or Spanish, are immediately translated into English, which is the platform's base language. They are then translated into a maximum of 14 languages by a team of translators who work in many countries remotely. Translators work anonymously, giving the appearance of a collective product and marking an important difference with the modern, individualized translation model, in contrast to the classical model, which was always collective (Shenhav-Shahrabani, 2019).

This multiple and instantaneous translation system is connected to a global distribution system. The columns are then sent to the newspapers, who buy a "pack" or "series" that they can translate into other languages not offered by $P S$. Newspapers can also ask $P S$ for a specific translation of a column. In total, the 508 newspapers form a global network of syndicated papers across all continents, making the content available to millions of people worldwide. The translations permit the flow of ideas, creating a real "circuit" because the ideas are then shared and discussed locally (although the phenomenon of the reception of these columns and their modes of appropriation and use of the ideas are beyond the scope of this study). Some newspapers not syndicated to the platform also publish its columns, sometimes without citing the platform. This is, for instance, the case of El Mercurio and La Tercera in Chile and even The Guardian in England.

2. The intellectuals who publish on PS stand out for the quality of their trajectories. $P S$ mostly asks prominent authors to contribute to the platform which, from its launch through to 2021, had published the work of 4538 columnists of whom around 80 publish monthly (this number, reported by the platform itself, was verified with a web scraping of our own making). Quality is provided by the main columnists, many of whom are leading economists, renowned public intellectuals, Nobel laureates, and former members of various presidential administrations 
(as ministers or economic advisers). In addition, PS receives around 300-400 unsolicited columns each month of which only around 30 make it to publication.

We can group intellectuals who publish on $P S$ into three types. First, there are Nobel laureates, like Michael Spence or Robert J. Shiller, who participate actively by writing for the platform and, because of their fame and prestige, form a distinctive category. Second, there is a category which, recalling Machiavelli's The Prince, we refer to as "councilors of the prince". These intellectuals are mostly former government ministers, advisers, state leaders, or even former presidents. Their opinions are valued mostly for their experience in government, on world affairs and international stages and in international forums. The third category are the "public intellectuals" who do not belong to the previous two categories in that they are neither Nobel Prize winners nor have served as government advisors but are the authors of best-selling books and have been consecrated by receiving international prizes. These three groups are summarized in the Table 1

This set of agents, who are generally very active in Project Syndicate (except for Jean Tirole), comprises predominantly men (only six women out of a total of 25 columnists) and economists (there are a couple of economic historians). All are very well-known, and their intellectual production circulates internationally.

3. An example that clearly illustrates this combination between a system of translation and global distribution, on the one hand, and prominent intellectuals, on the other, is Jeffrey Sachs. He is one of the most relevant global public intellectuals today and a world-renowned economics professor. Sachs uses a wide range of media to disseminate his work and ideas: (1) books, book chapters and edited books; (2) newspaper and magazine articles; (3) op-eds and syndicated columns; (4) interviews in the media and journal articles; (5) recorded lectures; and (6) reports. As we can see, he is an analog and digital public intellectual whose

Number of columns of economists in PS: the case of Jeffrey Sachs (1994-2020)

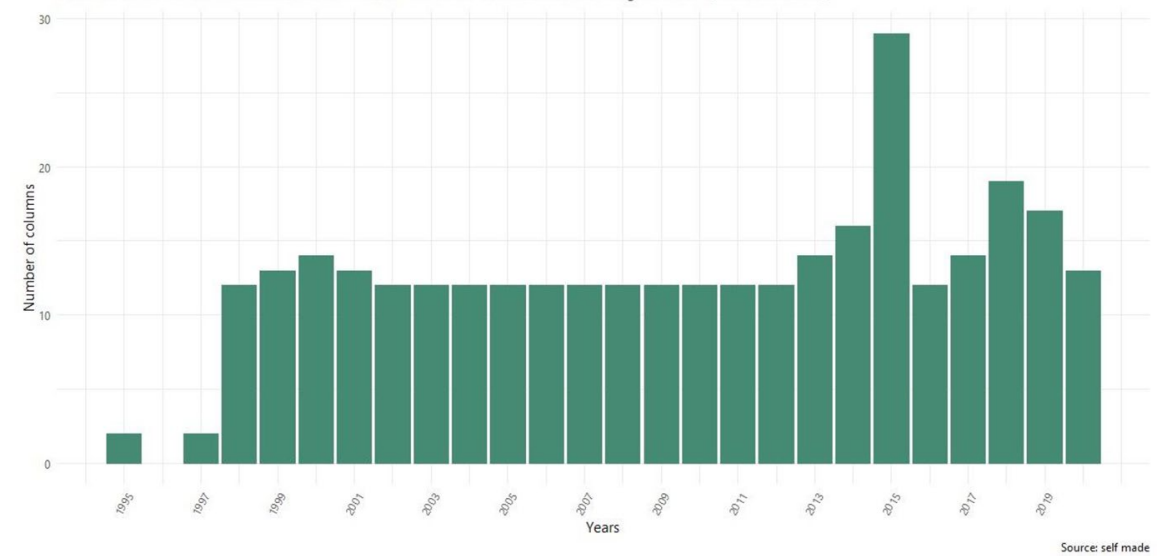

Source: Compiled by authors.

Fig. 1 Number of columns published by Jeffrey Sachs (1994-2020) 


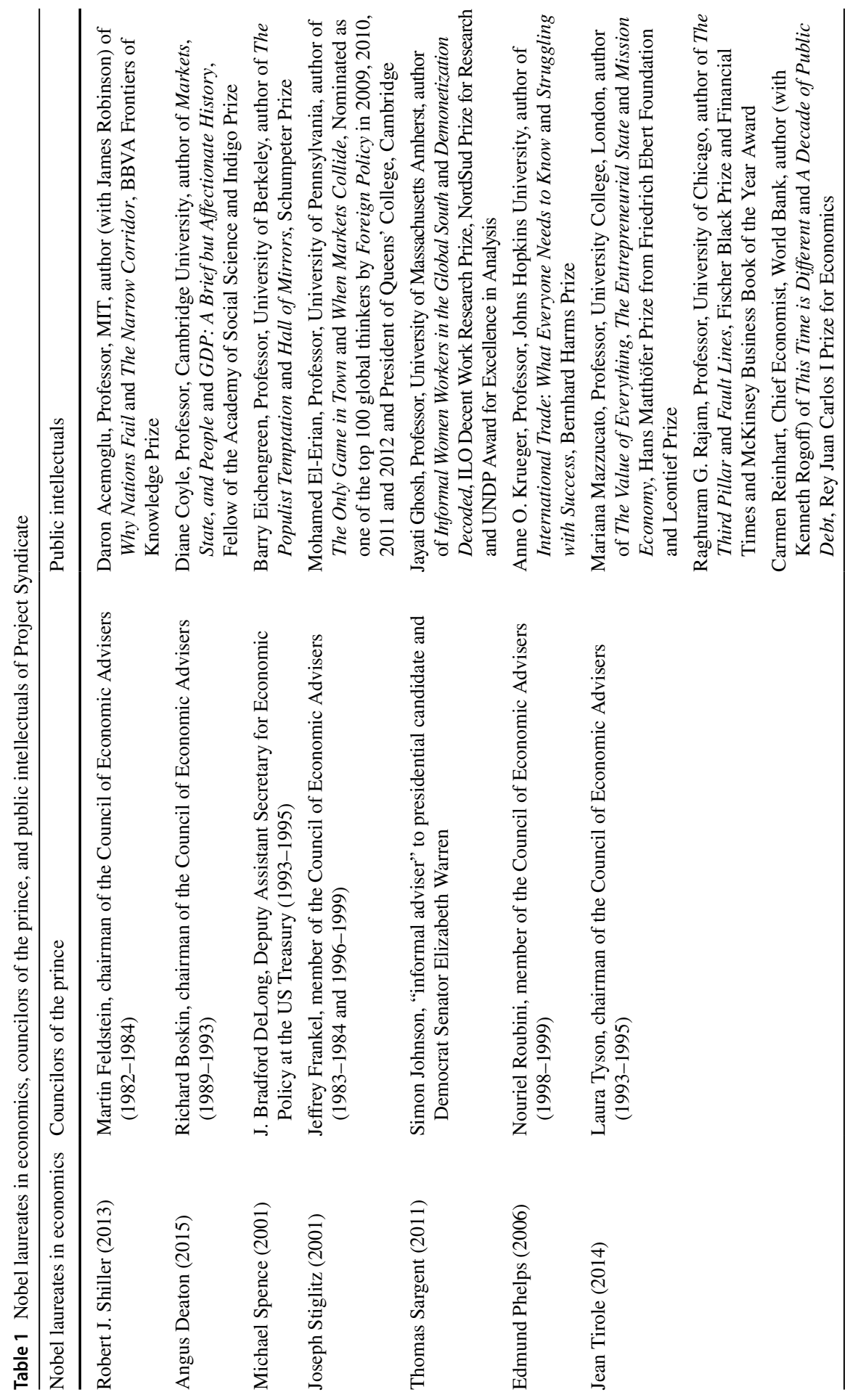




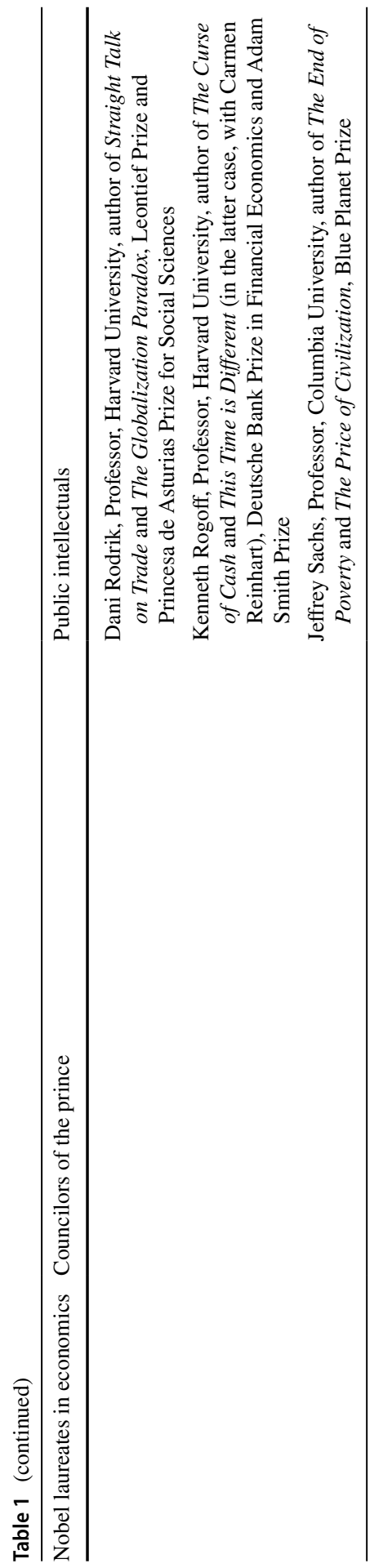


multimedia dissemination enables him to reach a very broad audience. Sachs is a very important and longstanding contributor to PS. As shown in Fig. 1, he has participated actively in the platform for the past 20 years, publishing 322 columns between 1994 and 2020, which have been translated into over ten languages (Fig. 2).

The importance of translation is key in understanding how $P S$ contributes to the rise of public intellectuals and how this platform constitutes a niche for them. Whereas Sachs's other work, such as newspaper articles and books, is sometimes not translated into many languages, the key fact about PS's columns is the number of languages into which they are translated. In this case, Sachs's columns are translated with some regularity into no less than eight languages.

These languages - Spanish, Russian, German, French, Chinese, Arabic and Italian - are important because they mean his columns can be read in the countries colored in blue in the map below where these are the official first language.

\section{Map 1. Countries where J. Sachs is translated}

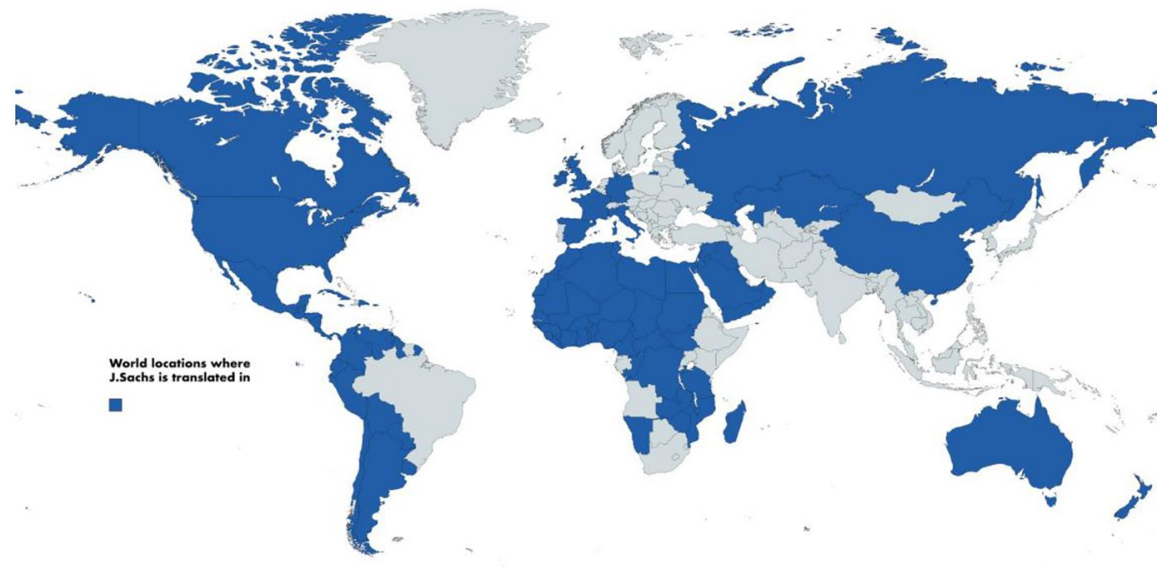

Source: Compiled by authors

As shown in the map, the circuit created by $P S$ 's translation system allows these columns to be read in most countries around the world. However, these countries are only the ones where the translation languages are the official language and do not include those where they are a second language as, for instance, in India, Norway, Sweden, or Finland where English is widely spoken. Summing up all these indicators, the PS columns of Jeffrey Sachs can potentially be accessed by most of the world population, like those of all the other authors who are translated into these same languages. 


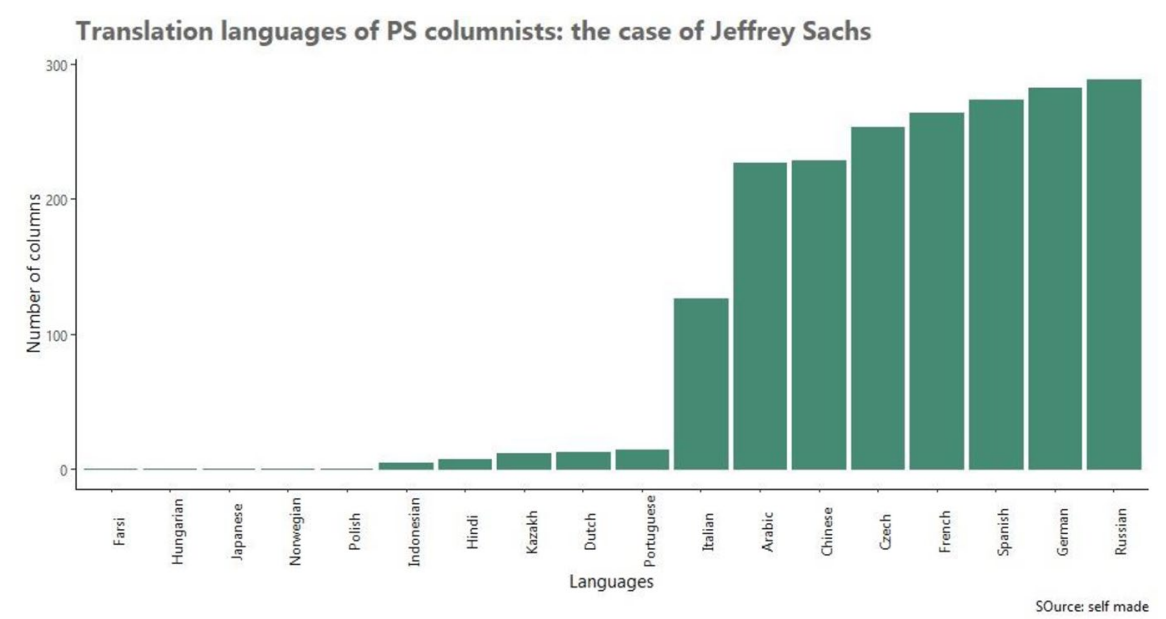

Source: Compiled by authors.

Fig. 2 Translation languages of PS columnists: the case of Jeffrey Sachs (2000-2020)

4. The case of Sachs shows that global dissemination is not the same as universality or totality, due to certain factors, emphases and specific paths along which ideas circulate. The notion of circuits expresses well the fact that the globality of circulation is determined by certain paths. In the case of $P S$, the paths are marked by topics (not all are equally relevant) (a); disciplines (some are far more heavily represented than others) (b); and the languages into which the columns are most frequently translated (where are clear trends) (c).

(a) $P S$ has a firm commitment to diversity within the spectrum of "democratic opinions" and its political span is very wide. Its contributors range from a very left-wing economist like Yanis Varoufakis (not included in our list because he does not meet the criteria for classification in any of the three groups) and Joseph Stiglitz to right-wing economists like Michael Boskin. However, it has published no columns emanating from the Trump administration or by non-democratic Russian leaders. Although it publishes economists from China, great care is exercised about the content. Little is published about politics in China and, when this occurs, it is through the informed pen of Richard N. Haass (since 2020) and Joseph S. Nye (since 2002). Beyond these boundaries, $P S$ can be said to welcome a diverse range of political and intellectual points of view.

(b) The platform covers many subjects since it has sections on topics as diverse as economics, politics, development, sustainability, culture, and innovation. However, economics has always been its core subject. There are several reasons for this, although the main one is that the columns it initially requested were economics-oriented and, as the platform grew, its economics columns attracted the largest readership. As Fig. 3 shows, the proportion of economists participat- 
ing was always important and has slowly increased, depending on the particular year and international events.

Just after the 2008-2009 international economic crisis, there was great demand for economic columns since readers wanted to understand what was happening amid the subprime collapse. There was, therefore, great interest in columns explaining the situation and proposing solutions as well as in new reflections on capitalism and its future. As shown in Fig. 3, it was precisely on the perimeter of the 2008 crisis that economists' production on this platform showed a marked increase (in 2010, they accounted for almost $40 \%$ of all columns published) before stabilizing at around a third of the total and then dropping in 2020 (due to the economic effects of the COVID-19 pandemic). In this sense, we note that crises are key moments for the emergence of public intellectuals, in this case, digital global public intellectuals... and economists (Hubbard, 2004).

(iii) An interesting fact about PS is the relative importance of the languages into which columns are translated. Arabic is the main language into which economists are translated, closely followed by Chinese and Spanish. This was particularly the case in 2008-2020 (Fig. 4).

Note: The figure shows the number of columns by economists that are translated into other languages by $P S$. With English as the base language, the columns can be translated into up to 18 languages. However, in this sample, there were four languages (Farsi, Hungarian, Japanese, and Polish) into which no column was translated. The other languages into which there were translations are, in ascending order, Norwegian (27); Hindi (34); Indonesian (124); Kazakh (145); Portuguese (502); Dutch (622); Italian (999); Czech (1 299); Russian (1 778); French (2 315); German (2 324); Spanish (2 696); Chinese (2 882) and Arabic (2 961).

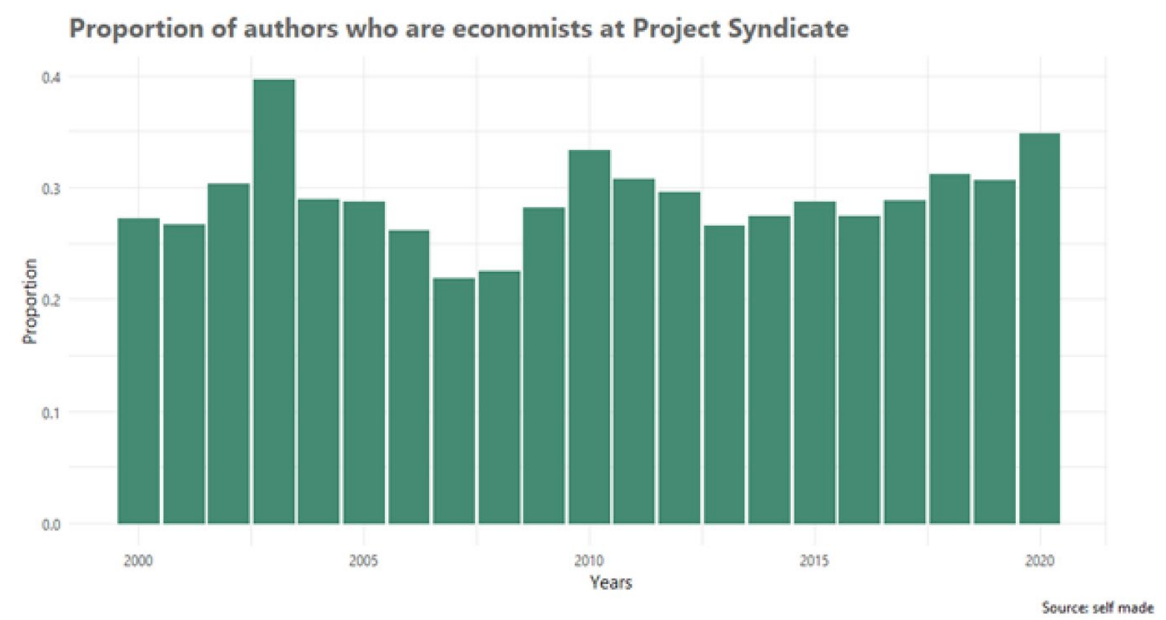

Source: Compiled by authors.

Fig. 3 Proportion of PS columns published by economists 


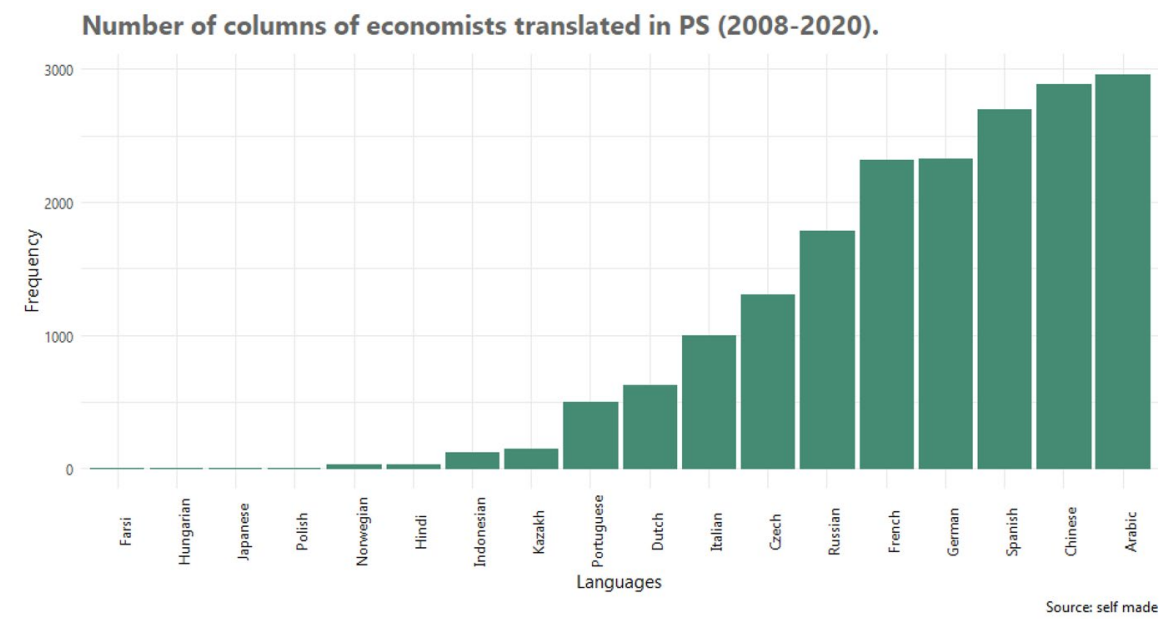

Source: Compiled by authors.

Fig. 4 Number of columns by economists translated by PS (2008-2020)

Interestingly, out of the columns published by economists between 2008 and 2020, almost 3000 were translated into Arabic and a slightly smaller number into Chinese. Contrary to the idea that Western economic ideas circulate only in the West, these columns are reaching the East in large numbers (although we do not know if that circulation, achieved through translation, finds a correlation at the reception level). This also belies the prejudice that the East and, more specifically, the Arab world are not sensitive to Western and democratic ideas. The PS platform, therefore, generates not only a global circuit of exchange of ideas but also subregional circuits that are linked to the translation process.

\section{Conclusion}

We can see why $P S$ is a unique type of platform; it enables small columns to circulate around the world and, through its quick syndication process, reach millions of readers simultaneously. Whereas the translation of a book takes a very long time and is only available through certain platforms such as Amazon, a small reader-friendly column is translated within 4-5 days and, thanks to PS's newspaper syndication system, reaches its global audience in less than a week.

In this context, we have introduced a key distinction for future research. Global digital public stages of this type cannot be considered universal because a series of factors and particularities determine the paths through which discourses typically circulate. We refer to these paths as global digital public circuits. As we have shown, $P S$ is an example of such a circuit. The circulation of ideas occurs there following north-south coordinates but, even within these coordinates, there are geographic and language emphases in that the columns, considered overall, are translated more into some languages than others. 
These digital global public stages have permitted the emergence of digital global public intellectuals, who also play a role in the circuits' specifications. They are mostly white, male, Anglo-Saxon economists, with outstanding academic and political careers at universities and in government. Global digital public stages do not extend over the globe as a homogeneous network but, rather, in the form of circuits whose nodes, concentrations, and particularities can be revealed by empirical research.

These stages or circuits are a necessary but not sufficient condition for the emergence of this new type of intellectual. To think otherwise would be to fall into a false technological determinism. With this conviction in mind, we consider it very relevant to study the trajectories of public intellectuals since the figure of the digital global public intellectual implies prior trajectories that involve stages and fields that are not public but academic, not global but local, and not digital but analog. We consider that the proposed model permits empirical analyses sensitive to the various possible trajectories that intellectuals may follow.

The notion of trajectory used in this article brings together under the same figure both the intellectual actors and the different stages on which they operate. The study of these trajectories according to the model we have proposed is not only useful in the empirical sense of being able to show how global circuits are inhabited by certain types of intellectual trajectories to the detriment of others. The model also has the conceptual utility of justifying why, when it comes to global digital circuits, we speak precisely of "circuits" and not of "fields" since the latter concept is better suited to stages that are more institutionalized than those seen at the global level where we believe it is more useful to speak of circuits. We consider that, in a context of globalization, it is important not to abuse the concept of "field" which, in this case, means taking seriously the fact that global "circuits" can exist for the circulation of ideas, categories, and concepts, without this implying the predominance in their origin of something like a global, international, and transnational intellectual "field". The Project Syndicate platform is a magnificent example of what is, in the end, a circuit for intellectual circulation that, albeit fed by national intellectual fields, has a logic of operation different from that of a field.

Acknowledgements We are indebted to Mario Fergnani, Andrés Díaz, and Felipe Márquez for their work in immersing themselves in the archives of the Project Syndicate platform.

Funding The author(s) disclosed receipt of the following financial support for research, authorship, and/ or publication of this article; the authors received financial support from the following research grants: Fondecyt Grant 1200493, Fondecyt Grant 1191490, and ANID/FONDAP Grant 15130009.

\section{Declarations}

Conflict of Interest The authors declare no competing interests.

\section{References}

Baert, P. (2012). Positioning theory and intellectual interventions. Journal for the Theory of Social Behaviour. 
Baert, P., \& Booth, J. (2012). Tensions within the public intellectual: Political interventions from Dreyfus to the new social media. International Journal of Politics, Culture and Society, 25, 111-126.

Bar-El, E., \& Baert, P. (2021). 'The fool' revisited: The making of Zizek as sacrificial public intellectual. Cultural Sociology, 15, 539-557.

Basaure, M., Joignant, A., \& Mascareño, A. (2021). Between distancing and interdependence: The conflict of solidarities in the COVID-19 pandemic. Sociological Perspectives.

Bourdieu, P. (1989). The corporatism of the universal: The role of intellectuals in the modern world. Telos: Critical Theory of the Contemporary, 81, 99-110.

Bourdieu, P. (2002). Les conditions sociales de la circulation internationale des idées. Actes De La Recherche En Sciences Sociales, 145, 3-8.

Brissaud, C., \& Chahsishe, J.-M. (2017). How to become an international intellectual? The case of Thomas Piketty and 'Capital in the Twenty-First Century'. Sociologica, Fascicolo 1, 1-38.

Buchholz, L. (2016). What is a global field? Theorizing fields beyond the Nation-State. Sociological Review Monograph, 64, 31-60.

Burnham, C. (2014). Slavoj Žižek as an internet philosopher. In M. Flisfeder \& L. P. Willis (Eds.), Žižek and the Media: A Reader (pp. 201-210). Palgrave.

Burnham, C. (2018). Does the Internet have an Unconscious? Slavoj Žižek and Digital Culture. Bloomsbury.

Casanova, P. (2002). Consécration et accumulation de capital littéraire. Actes De La Recherche En Sciences Sociales, 144, 7-20.

Casanova, P. (2008). La république mondiale des lettres. Editions du Seuil.

Dézalay, Y., \& Garth, B. G. (1996). Dealing in virtue: International commercial arbitration and the construction of a transnational legal order. The Chicago University Press.

Dézalay, Y., \& Garth, B. G. (2002). The internationalization of palace wars: Lawyers, economists, and the contest to transform latin American states. The Chicago University Press.

Driessens, O. (2013). Celebrity capital: Redefining celebrity using field theory. Theory and Society, 42(5), 543-560.

Eyal, G., \& Buchholz, L. (2010). From the sociology of intellectuals to the sociology of interventions. Annual Review of Sociology, 36, 117-137.

Finley, M. (1983). Politics in the Ancient World. Cambridge University Press.

Fleck, C., \& Hess, A. (2014). Knowledge for Whom? Public Sociology in the Making, Farnham: Ashgate.

Gans, H. (2001). In the future of the public intellectual: A forum”, The Nation, 26 Jan.

Hubbard, G. R. (2004). The economist as public intellectual. The Journal of Economic Education, 35(4), 391-394.

Jacoby, R. (1987). The last intellectuals. American culture in the age of academe. Basic Books.

Joas, H. (1996). The creativity of action. Polity.

Joignant, A., \& Basaure, M. (2021). Crisis and public intellectuals: From the transnational intellectual field to the digital global public circuit. Sociology Compass, 15, 5. https://doi.org/10.1111/soc4. 12875

Korom, P. (2014). How spaces of opinion shape public intellectuals: A field-based approach to project syndicate-Op-Eds. In: Christian Fleck \& Andreas Hess (eds), Knowledge for Whom? Public Sociology in the Making, Farnham: Ashgate 229-251.

Krause, M. (2018). How fields vary. British Journal of Sociology, 69, 3-22.

Manin, B. (1995). Principes du gouvernement représentatif. Flammarion.

Mirowski, P., \& Plewe, D. (2009). The Road from Mont Pelerin. The making of the neoliberal thought collective, Cambridge, Massachusetts, Harvard University Press, 2009.

Ober, J. (2007). Athenian legacies: Essays on the politics of going on together. Princeton University Press.

Oosthuizen, A. (2021). The fabric of dissent: public intellectuals who have shaped SA's history, HSRC Review, 19(1), 22-24.

Piketty, T. (2013). Le capital au XXIème siècle. Seuil.

Saï, E. (2005). The public role of writers and intellectuals. In S. Bermann \& M. Wood (Eds.), Nation, Language, and the Ethics of Translation (pp. 15-29). Princeton University Press.

Sapiro, G. (2013). Le champ est-il national? Actes de la recherche en sciences sociales, 70-85.

Sapiro, G., Leperlier, T., \& Brahimi, M. A. (2018). Qu'est-ce qu'un champ intellectuel transnational? Actes de la recherche en sciences sociales, 4-11.

Schwarz, O. (2021). Sociological theory for digital society: The codes that bind us together. Polity Press. 
Shenhav-Shahrabani, Y. (2019). The neoclassical bias in translation. Journal of Levantine Studies, 9(1), $5-18$.

Shehab, E., \& Nazzal, R. (2020). The translation of game/sport metaphors in English business texts into Arabic: A cognitive approach. Journal of Foreign Language Teaching and Translation Studies, 5(1), $21-40$.

Stedman Jones, D. (2012). Masters of the universe: Hayek, Friedman, and the birth of the neoliberal politics. Princeton University Press.

Swartz, D. L. (2021). Les universitaires trumpistes: des opposants à la diversité progressiste. AOC, 15 Jun.

Townsley, E. (2015). Public intellectuals, media intellectuals, and academic intellectuals. Comparing the space of opinion in Canada and the United States. In: Speaking Power to truth: Digital discourse and the public intellectual, Keren M. y Hawkins, R. AU PRESS.

Warner, M. (2002). Publics and counterpublics. Public Culture, 14(1), 49-90.

Zelinsky, D. (2020). The sociology of intellectuals in the 20th and 21st century. Sociology Compass, 14(4).

Publisher's Note Springer Nature remains neutral with regard to jurisdictional claims in published maps and institutional affiliations. 